\title{
Tough, natural-fibre composites based upon epoxy matrices
}

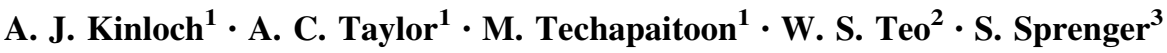

Received: 15 April 2015/Accepted: 26 June 2015/Published online: 15 July 2015

(C) The Author(s) 2015. This article is published with open access at Springerlink.com

\begin{abstract}
Flax fibres and cellulose fibres were used to manufacture composites with particle-modified epoxy matrices in order to develop 'green' composites which possess relatively high values of interlaminar fracture energy, $G_{\mathrm{c}}$. The flax used had a unidirectional architecture of continuous yarns spun from short, interlocked fibres. The regenerated cellulose consisted of continuous and nontwisted pure cellulose fibres in a plain-woven architecture. The natural-fibre-reinforced-polymer (NFRP) composites employed an anhydride-cured diglycidyl ether of bisphenol-A epoxy as the matrix. The epoxy polymeric matrix was modified with (a) silica nanoparticles, (b) rubber microparticles, and (c) a combination of both of these types of particles to give a hybrid-toughened epoxy matrix. The composites were manufactured via a resin infusion under flexible-tooling (RIFT) process. Preliminary studies on the NFRP composites manufactured using the initial-RIFT process clearly showed the deleterious effect that moisture present in the natural fibres had upon the properties of the NFRP composites, since the trapped water cannot escape from the composite panel. Hence, an optimised-RIFT process was developed whereby the natural fibres were dried in a fan oven prior to being employed in the RIFT process. This reduced the water content of the fibres from around 9 to $10 \mathrm{wt} \%$ to about $1 \mathrm{wt} \%$. Significant
\end{abstract}

A. J. Kinloch

a.kinloch@imperial.ac.uk

1 Department of Mechanical Engineering, Imperial College London, South Kensington Campus, London SW7 2AZ, UK

2 Singapore Institute of Manufacturing Technology, 71 Nanyang Drive, Singapore 638075, Singapore

3 Evonik Hanse GmbH, Charlottenburger Straße 9, 21502 Geesthacht, Germany improvements in the physical and mechanical properties were recorded for the NFRP composites manufactured using this optimised-RIFT process. Indeed, in particular, very dramatic improvements in the $G_{\mathrm{c}}$ of the NFRP composites were measured, especially when the epoxy polymeric matrix was modified using the silica nanoparticles and/or rubber microparticles. For example, a steady-state propagation value of $G_{\mathrm{c}}$ of about $1935 \mathrm{~J} / \mathrm{m}^{2}$ was measured for the flax-fibre composite with the hybrid epoxy matrix, compared to values of 1110 and $535 \mathrm{~J} / \mathrm{m}^{2}$ for the flax-fibre and glass-fibre composites based on the unmodified (i.e., the 'control') epoxy matrix, respectively.

\section{Introduction}

Due to an increasing environmental concern that sustainable materials should be found to replace petroleum-based ones, there has been much research in recent years on composites that contain natural fibres and/or natural polymers as the matrix. Since suitable natural polymers still appear to be relatively expensive for commercial products, using natural fibres as the reinforcement in composites that employ synthetic polymers as the matrix is an attractive concept for many applications, especially in mass-transport applications and commercial vehicles. Previous literature has reported the use of both continuous flax and regenerated cellulose fibres (CeF) in natural-fibre-reinforcedpolymer (NFRP) composites [1-5], with a growing interest in studying the textile-weave forms of these fibres in polymeric systems for structural applications. For example, the recent work by Shah [6] has developed 'Ashby-type' selection charts for NFRP composites and has shown that flax and CeF rank the highest on the basis of their tensile modulus and strength properties, followed by hemp and 
kenaf fibres. Furthermore, due to the relatively low density of natural fibres, their specific properties may approach those of glass-fibre-reinforced-polymer (GFRP) composites. Flax fibres (FF) have also been reported [7] to perform better than jute or sisal fibres in composites based upon thermosetting polymeric matrices in terms of fire resistance.

The exciting potential of NFRP composites based upon textile-woven fibres and employing thermosetting polymeric matrices has encouraged efforts to provide data on other engineering properties such as fatigue [8-10], compression [11], damping [12], fracture toughness [13-15], impact $[16,17]$, and thermal/flammability $[7,18]$ properties. The effects of various types of fibre architecture, such as the weave form, lay-up, and mixtures of fibre types [10, 11, 13, 19], have also been reported. So far, the performance of NFRP composites strongly associated with interlaminar energy absorption and damage development, such as low velocity impact, crashworthiness, and damping, appears to be very promising, and has been reported $[13,20,21]$ to even surpass the performance of GFRP and metal alloys. For example, Yan and Chouw [21] showed that the specific absorbed energy of flax-fabric reinforced epoxy tubes was $41 \mathrm{~J} / \mathrm{g}$, which was comparable to the upper range of steel and aluminium tubes, i.e., being 38 and $43 \mathrm{~J} / \mathrm{g}$, respectively.

Liu and Hughes [13] measured the fracture toughness of woven-flax/epoxy composites and reported strong anisotropic effects, which were dominated by the fibre properties, in agreement with earlier work [14]. Zhang et al. [15] have investigated the interlaminar fracture energy, $G_{\mathrm{c}}$, of unidirectional (UD) flax and glass fibres embedded in a phenolic polymeric matrix and reported of values 550 and $400 \mathrm{~J} / \mathrm{m}^{2}$, respectively. It was observed that crack propagation in the flax composite was accompanied by extensive fibre bridging. Li et al. [22] have successfully increased the interlaminar facture energy, $G_{\mathrm{c}}$, of UD flax-fibre/epoxy matrix composites by about $30 \%$, to give a value of $1350 \mathrm{~J} / \mathrm{m}^{2}$, by introducing $1 \mathrm{wt} \%$ of multi-walled carbonnanotubes onto the surfaces of the FF. Kafi et al. [23] have studied woven jute-fibre/polyester-matrix composites and achieved values of $G_{\mathrm{c}}$ of about $1800 \mathrm{~J} / \mathrm{m}^{2}$. Regenerated CeF for NFRP composites have, so far, only been widely studied with biodegradable or thermoplastic matrix systems. One factor being that the extra processing needed for such fibres, compared to FF, may lead to an increase in their relative cost. Also, their mechanical properties are generally lower than those of FF; hence, various strategies such as fibre treatments and using a mixture of fibre types have been proposed to improve the overall performance of such composites [24-27]. However, in terms of specific modulus and strength, FF usually still retain an advantage compared to regenerated $\mathrm{CeF}$.
Apart from wet-impregnation $[8,12,28]$, NFRP composites based upon thermosetting matrices have been successfully processed via the relatively inexpensive infusiontype manufacturing methods such as resin infusion under flexible-tooling (RIFT) [10, 22, 29] or closed mould resintransfer moulding $[12,18,20]$. Although moisture in natural fibres, present when the NFRP composite is manufactured, is generally considered to be detrimental to the fibre-matrix interface adhesion, drying the fibres prior to infusion has not been conventionally practised. Since, any benefits from pre-drying the fibres have not been well established due to the lack of detailed studies. However, in general, the rapid absorption of water by these natural fibres is well established, as is the effect that the absorbed moisture in the natural fibres may have upon the subsequent properties of the NFRP composites [e.g., 30-34]. According to Baley et al. [30], drying at around $150{ }^{\circ} \mathrm{C}$ is required to remove bound water, but drying at $105^{\circ} \mathrm{C}$ for $14 \mathrm{~h}$ may already cause a decrease in strength of FF by $42-46 \%$, with a corresponding decrease of $36 \%$ in the UD composites. A decrease in the tensile failure strength of FF dried at $103{ }^{\circ} \mathrm{C}$ was also reported by Masseteau et al. [31], where a $17 \%$ loss in strength was accompanied by a $20 \%$ increase in their modulus, compared to the 'wet' state. Both studies [30, 31] showed that despite the changes observed in the fibre properties, the moduli of the resulting UD flax/epoxy composites using either 'wet' or 'dried' fibres were comparable. For the purpose of removing moisture near the surface of $\mathrm{FF}$, immediately prior to manufacturing the composite, moderate temperatures between 40 and $80{ }^{\circ} \mathrm{C}$ have been typically used with drying periods varying from 2 to $48 \mathrm{~h}[17,18,32,33]$.

Two types of natural fibres were employed in the present work: FF and regenerated CeF. The FF was in the form of continuous yarns spun from short, interlocked fibres which were woven into a fabric. The weaving architecture of the flax-fibre fabric was UD. The regenerated CeF employed was a continuous and non-twisted pure $\mathrm{CeF}$ in a $\mathrm{PW}$ architecture. The NFRP composites were manufactured employing a RIFT process and were based on an anhydride-cured diglycidyl ether of bisphenol-A (DGEBA) epoxy thermosetting polymer as the matrix.

The main aim of the present work is to produce NFRP composites based upon these materials which possess a relatively high value of the interlaminar fracture energy, $G_{\text {c }}$. The RIFT manufacturing method was selected since this is a convenient, low-cost tooling method for manufacturing composite materials which is based upon drawing resin into a dry reinforcement on an evacuated vacuumbagged tool, using only the partial vacuum to draw-in the resin. To achieve this aim of producing NFRP composites which possess a relatively high value $G_{\mathrm{c}}$, two aspects will be of particular interest. Firstly, the role that the water 
absorbed by the natural fibres prior to manufacture via the RIFT process has upon the mechanical properties of the NFRPs will be investigated, and the RIFT process optimised as necessary. Secondly, previous work [35-38] has shown that the toughness of the epoxy polymeric matrix also plays a key role in producing a composite material with a relatively high toughness. Thus, in order to increase the toughness of the epoxy polymeric matrix, and possibly the resulting NFRP composite, the matrix will be modified with (a) silica nanoparticles, (b) rubber microparticles, and (c) a combination of both of these types of particles to give a hybrid-toughened epoxy matrix. Finally, it should be noted that, for comparative purposes, GFRP composites, based upon the same chemical type of epoxy resin matrices and manufactured using the RIFT process, were also studied. The present investigation will demonstrate that, when the manufacturing and polymer matrix are optimised, it is possible to achieve relatively very high values of $G_{\mathrm{c}}$, close to about $2000 \mathrm{~J} / \mathrm{m}^{2}$ for the NFRP composites.

\section{Experimental}

\section{Fibres}

Two different cellulose-based fibres were used to prepare the NFRP composites. These natural fibres were selected on the basis of wishing to evaluate commercial sources of 'natural' (i.e., flax) and 'manufactured' (i.e., regenerated) $\mathrm{CeF}$, since both are regarded as equally promising candidates for cellulose-based reinforcements. However, variations in the form and properties of natural $\mathrm{CeF}$ remain a technical challenge. For example, manufactured cellulose is usually more process-intensive (and hence 'less green') compared to FF. However, the manufacturing process for the regenerated $\mathrm{CeF}$ does permit greater control over the consistency of the fibre properties, the fibre count, fibre dimensions, and surface finish. The naturally occurring cellulosic-based fibres, such as FF, and the regenerated $\mathrm{CeF}$ also differ in their cellulose types: 'cellulose I', which is an assembly of crystallites and disordered amorphous material, is found in naturally occurring cellulosic-based fibres, while 'cellulose II', which is a more stable form of the cellulose crystal, is found in regenerated cellulose [39]. Further discussions on the selection of the natural-fibre reinforcements may be found in [40]. Both the cellulosebased fibres were employed as received from the manufacturers with no further surface treatment being employed.

The FF used in the present study was in the form of continuous yarns spun from short interlocked fibres, with a diameter of $17 \pm 7 \mu \mathrm{m}$, which were woven into a fabric, and was supplied by Composites Evolution, UK [41]. The weaving architecture of the flax-fibre fabric used in the present study was UD, see Fig. 1a. The flax-fibre UD (FFUD) fabric has the majority of fibres running in one direction only. A very small number of fibres run in the perpendicular direction merely to hold the primary, UD, fibres in position. The regenerated $\mathrm{CeF}$ was a continuous and non-twisted pure CeF, with a diameter of $10 \pm 1 \mu \mathrm{m}$, in a PW fabric architecture, see Fig. 1b, and was supplied by Porcher Industries, France [42], under the tradename 'Greenlite ${ }^{\mathrm{TM}}$, This regenerated cellulose plain-woven (CeF-PW) fabric had fibres in the warp and weft directions, where each warp fibre passes alternately under and over each weft tow. Two different weaving architectures of glass-fibre fabric, namely UD and PW, were selected in order to manufacture GFRP composites that would match the weaving architectures of the NFRP composites. They were both supplied by SP Systems, UK, and employed E-glass fibres with a diameter of $15 \pm 2 \mu \mathrm{m}$.

\section{Matrices}

The matrix materials were based upon anhydride-cured DGEBA epoxy resin formulations. The epoxy resin was a standard DGEBA with an epoxide equivalent weight (EEW) of 185 g/eq, 'LY556' supplied by Huntsman, UK. The reactive liquid carboxyl-terminated butadiene-
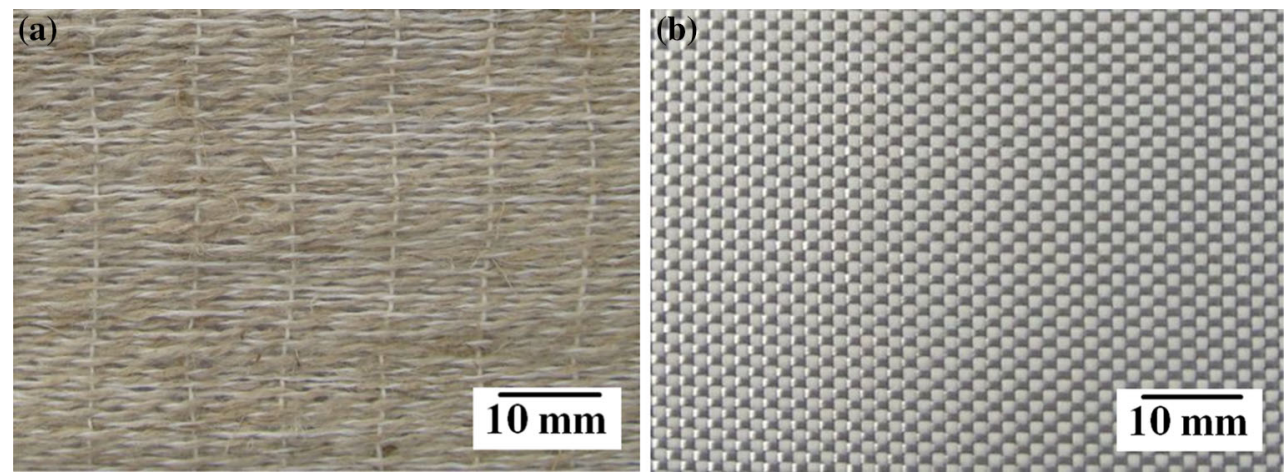

Fig. 1 a The unidirectional flax-fibre (FF-UD) fabric, and $\mathbf{b}$ the plain-woven cellulose-fibre (CeF-PW) fabric 
acrylonitrile (CTBN) rubber (which gives rise to phaseseparated, micrometre-sized rubber particles upon curing) was obtained as a CTBN-epoxy adduct with a rubber concentration of $40 \mathrm{wt} \%$ in a DGEBA epoxy resin, namely 'Albipox 1000' (EEW = $330 \mathrm{~g} / \mathrm{eq}$ ) from Evonik, Germany. The silica $\left(\mathrm{SiO}_{2}\right)$ nanoparticles were obtained at a concentration of $40 \mathrm{wt} \%$ in a DGEBA epoxy resin $(\mathrm{EEW}=295 \mathrm{~g} / \mathrm{eq})$ as 'Nanopox F400' from Evonik. The curing agent was an accelerated methylhexahydrophthalic acid anhydride, 'Albidur HE 600' (AEW = $170 \mathrm{~g} / \mathrm{eq}$ ), also supplied by Evonik. The DGEBA epoxy resin was mixed with the epoxy containing the silica nanoparticles and/or the CTBN-epoxy adduct to give the required levels of silica $\left(\mathrm{SiO}_{2}\right)$ nanoparticle and/or rubber microparticle modification. A stoichiometric amount of the curing agent was added to the mixture, which was stirred thoroughly and degassed at $50{ }^{\circ} \mathrm{C}$ and $-1 \mathrm{~atm}$. Four types of epoxy matrix formulations were prepared: (a) an unmodified epoxy (i.e., the 'control', termed 'Si0R0'), (b) an epoxy with only silica nanoparticles (termed 'Si10R0'), (c) an epoxy with only rubber microparticles (termed 'Si0R9'), and (d) a hybrid epoxy containing both silica nanoparticles and rubber microparticles and (termed 'Si10R9'), where 10 and $9 \mathrm{wt} \%$ represent the amount of the modifier by percentage weight of the total formulation. The appropriate epoxy matrix formulation was infused into the fibre fabric, see below, at $50{ }^{\circ} \mathrm{C}$ and then cured at $100{ }^{\circ} \mathrm{C}$ for $2 \mathrm{~h}$, followed by a post-cure at $150{ }^{\circ} \mathrm{C}$ for $10 \mathrm{~h}$. Before testing, all the composite specimens for all the various tests were conditioned by heating them for $12 \mathrm{~h}$ at $75{ }^{\circ} \mathrm{C}$ and then allowing them to cool at $23{ }^{\circ} \mathrm{C}$ and $55 \% \mathrm{RH}$ for about $4 \mathrm{~h}$. (The processing temperature for the NFRP composites is, of course, dictated by the cure schedule needed for the epoxy resin matrix. The relatively high-temperature curing epoxy systems used in the present study have been used in previous research and this readily enables comparisons to be made to previously reported results. They are also widely used in the electronics and sports good industries.)

\section{The initial-RIFT manufacturing process}

The RIFT manufacturing process which was employed to prepare all the composite panels was based upon the work of Masania et al. [37, 43], see Fig. 2. The laboratory temperature was maintained at $21 \pm 2{ }^{\circ} \mathrm{C}$ and the relative humidity at $55 \pm 5 \%$. Layers of the selected fabric were laid in between the top and bottom consumable stacks, see Fig. 2c. For the fracture tests, the layers of fabric contained a 50-mm-wide poly(tetrafluoroethylene) (PTFE) film, with a thickness of $10 \mu \mathrm{m}$, inserted along one side, in between the middle layers of the fabric, to act as a pre-crack in the double-cantilever beam (DCB) test specimens. The complete assembly was bagged-up and vacuum sealed, using a high-temperature, pressure-sensitive adhesive tape, with the outlet connected to the vacuum pump and with the inlet connected to the resin container via a valve. The assembly was placed on a preheated metal plate at $50{ }^{\circ} \mathrm{C}$ and subjected to a vacuum, giving a pressure of approximately $-0.1 \mathrm{MPa}$ relative to atmospheric pressure, and the inlet valve was opened to allow the resin, also at $50{ }^{\circ} \mathrm{C}$, to infuse into the fabric layers until the resin formulation visually appeared to wet fully all the layers of fabric reinforcement,
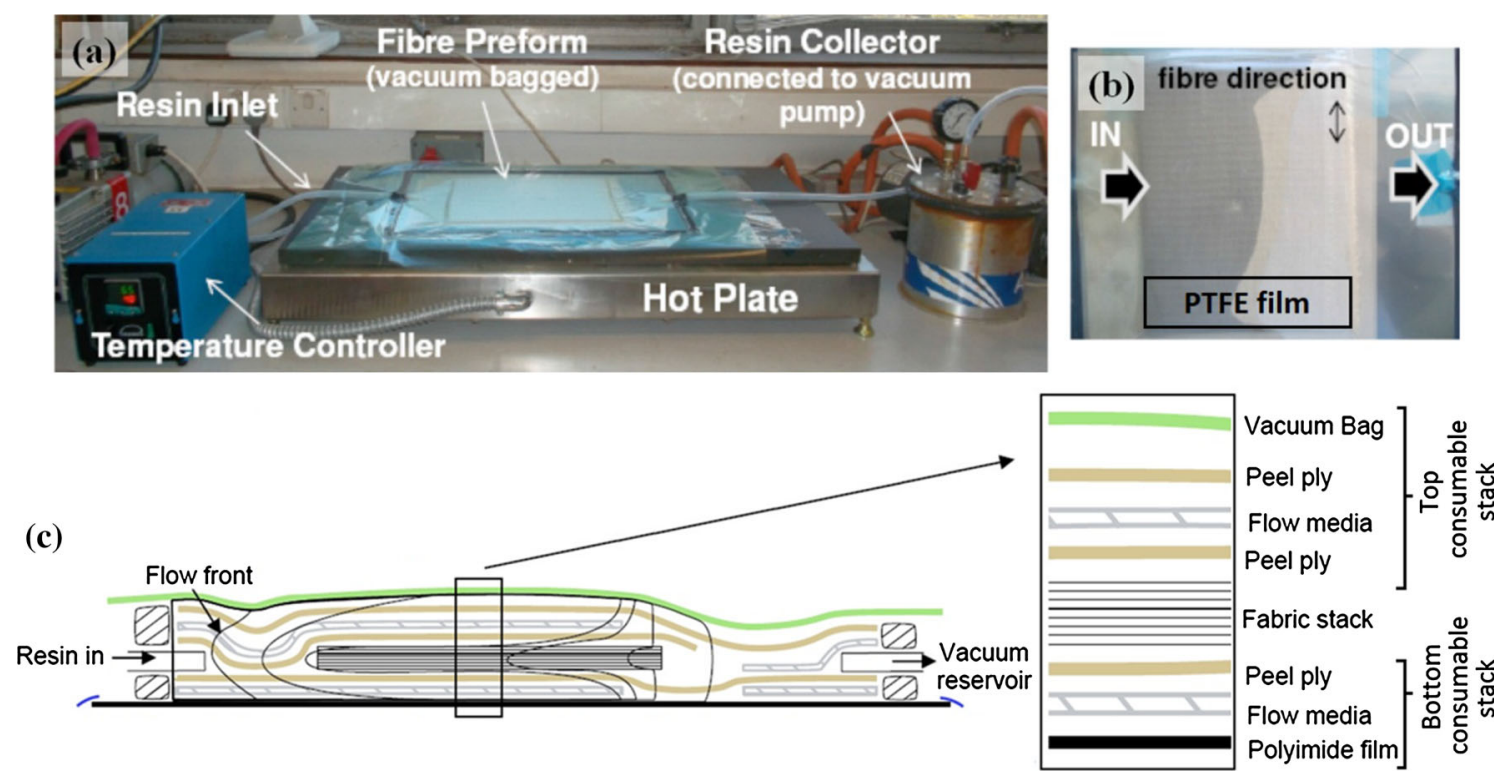

Fig. 2 The RIFT manufacturing process: a set-up, $\mathbf{b}$ top view showing the flow-front of the epoxy resin and $\mathbf{c}$ schematic of side-view, through thickness, of mid-plane and the schematic flow front of the epoxy resin [43] 
see Fig. 2b. The inlet was then closed to stop further infusion of the epoxy resin. [The time between the fibres being placed in the RIFT equipment to achieving complete infusion of the epoxy resin formulation was about $45 \mathrm{~min}$ for the relatively low viscosity unmodified epoxy formulation (i.e., the 'Si0R0' formulation) up to about $120 \mathrm{~min}$ for the highest viscosity, hybrid epoxy formulation (i.e., the 'Si10R9' formulation).] Next, the temperature was raised to cure the epoxy matrix under the imposed vacuum. The fabricated composite panels were cut into specimens using either a wet diamond-saw machine (for the GFRP composites) or a laser-cutting machine to avoid contact with moisture (for the NFRP composites).

\section{The optimised-RIFT manufacturing process}

The results to be discussed later clearly show the deleterious effect that moisture present in the natural fibres may have upon the properties of the NFRP composites, and in the RIFT process, the trapped water cannot escape from the composite panel. Thus, it may only diffuse into the epoxy matrix and/or be released as steam. Hence, in the 'optimised-RIFT' manufacturing process, the FF (i.e., the FFUD fabric) and the $\mathrm{CeF}$ (i.e., the $\mathrm{CeF}-\mathrm{PW}$ fabric) were dried in a fan oven at $75{ }^{\circ} \mathrm{C}$ for $12 \mathrm{~h}$ prior to being employed in the RIFT process, as described above. This drying schedule was selected on the basis of a series of tests [40] which showed that the moisture content was reduced to a very low level of $1 \mathrm{wt} \%$ by using this schedule. Also, no degradation of the natural-fibre fabrics was observed using this schedule and this drying time was not too excessive from a commercial manufacturing viewpoint. In all other respects, the optimised-RIFT manufacturing process was identical to the initial RIFT process described above.

\section{Physical property studies}

The details of all the experimental methods employed to obtain the various physical parameters are described in detail in [40]. The weight percentage of absorbed water in the fibres was simply found by the conventional technique of weighing samples of the fibres as a function of the drying time. The fully dried fibres were obtained by heating them in a fan oven at $75^{\circ} \mathrm{C}$ for at least 3 days. The void content, $V_{\mathrm{v}}$, of the manufactured composite is widely accepted to be a useful quality-control measurement of cured composites. However, instead of the resin-burn-off technique commonly used for composites reinforced with synthetic fibres, optical microscopy was used for the NFRP composite panels due to the low degradation temperature of around $200{ }^{\circ} \mathrm{C}$ for the natural fibres $[40,44,45]$. The same method was also used for the GFRP composite panels in order to keep the results consistent. For similar reasons, the fibre volume fraction, $V_{\mathrm{f}}$, was calculated using the measured density and the specimen geometry. The determination of the densities, $\rho$, of the composites was conducted in accordance with ASTM D2320 [46] using an 'AccuPyc II 1340' gas pycnometer from Micromeritics, USA. The values of the glass transition temperature, $T_{\mathrm{g}}$, of the epoxy matrices were measured by differential scanning calorimetry using a 'DSC Q200' equipment from TA Instruments, USA, in accordance with ASTM E1356 [47].

\section{Mechanical property studies}

The details of all the experimental methods employed to obtain the various mechanical property parameters that were of interest in the present work are described in detail in [40]. The flexural modulus, $E_{\text {flex }}$, of the various composites was measured in accordance with ASTM D790 [48] and the uniaxial tensile tests were conducted in accordance with ASTM D3039 [49]. The mode I interlaminar fracture energy, $G_{\mathrm{c}}$, for steady-state crack propagation through the composite materials was measured using the DCB test, in accordance with BSI-ISO 15024 [50]. The $150 \mathrm{~mm} \times$ $20 \mathrm{~mm}$ DCB specimens were cut from the fabricated composite panels, which were between about 3- to 5-mm thick depending upon the composite type. Along the first 50-mm length of the specimens, a PTFE film had been inserted between the middle plies of the fibre stack, prior to resin infusion, to serve as a pre-crack. The pre-cracked ends of the specimens were adhesively bonded to aluminium end-blocks, and a thin layer of typewriter erasing liquid was painted on one side of the specimen. A crack length-scale was drawn at intervals on the white surface to readily allow the visual measurement of crack growth during the test, aided by a low-power travelling optical microscope. The interlaminar fracture energy, $G_{\mathrm{c}}$, was calculated using the 'corrected beam theory' method, in accordance with BS-ISO 15024 [50]. The tests revealed that the composites exhibited 'R-curve' behaviour due to the effects of fibre bridging. Therefore, the values of $G_{\mathrm{c}}$ which are given in the present paper are for steady-state crack propagation, when a maximum, plateau level of the value of $G_{\mathrm{c}}$ had been attained. For the NFRP composites manufactured using the optimised-RIFT process, due to the high values of $G_{\mathrm{c}}$ that they exhibited, the NFRP DCB test specimens had UD GFRP strips bonded on to each side of the DCB test specimen, using a room-temperature curing epoxy adhesive. This prevented inelastic deformation of the arms of the DCB test occurring, which would have made the test results invalid according to the BS-ISO Standard [50]. 


\section{Imaging studies}

An atomic force microscope (AFM) was used to inspect the morphology of the particle-modified matrices of the composites. The sample preparation involved microtoming the surfaces of the samples using a 'PowerTome XL' ultramicrotome from RMC Products, USA, to give a very smooth surface. A tapping-mode scan of the surfaces of the microtomed sample was conducted using a 'Multi-Mode 8' scanning probe microscope from Veeco, USA, with a silicon probe that had a 5-nm-diameter tip. The height and phase images were captured at a $512 \times 512$ pixel resolution at a scanning rate of $1 \mathrm{~Hz}$, and the image analysis was conducted using the 'NanoScope IV' software. The fracture surfaces of the DCB specimens were inspected using either a 'S-3400N' scanning electron microscope (SEM) from Hitachi High Technologies, UK, or a high-resolution 'LEO Gemini 1525 ' field emission gun scanning electron microscope (FEG-SEM) from Carl Zeiss, Germany. Specimens were cut from the tested specimens using a diamond-saw cutting machine and were mounted onto a SEM sample stub using conductive adhesive tabs. They were then coated with chromium using a 'Quorum Q150T S' turbo-pumped sputter-coater, Quorum Technologies, UK, to give a coating of sputtered chromium which was approximately $20-\mathrm{nm}$ thick. Conductive silver paint was also used to make a conductive link from the surface of the sample to the sample stub. These precautions made the specimens less likely to charge during imaging when examined using the SEM.

\section{Results and discussion}

\section{Initial-RIFT studies}

Results for the NFRPs manufactured using the initial-RIFT process, as described above, are shown in Table 1. There are several noteworthy points. Firstly, the quality of the NFRP composites was relatively very poor. This may be seen from the relatively high void, $V_{\mathrm{v}}$, contents that were measured and the fact that the CeF-PW composites based upon the 'Si0R9' and 'Si10R9' epoxy matrices could not be tested due to the poor quality of the resulting composite panels (i.e., they fell apart during cutting and specimen preparation). Secondly, for the other NFRP composites, the values of the interlaminar fracture energy, $G_{\mathrm{c}}$, are relatively very low, with the values measured ranging from about 20 to $250 \mathrm{~J} / \mathrm{m}^{2}$. Indeed, these values may be compared to the values for the GFRP composites, see Table 2, where values of $G_{\mathrm{c}}$ of about 535 to over $1300 \mathrm{~J} / \mathrm{m}^{2}$ were measured. Thirdly, the relatively low void, $V_{\mathrm{v}}$, contents for the GFRPs, manufactured via employing the same conditions in the RIFT process as used for the NFRPs, were considered to be an important observation and led to a detailed study of the physical properties of the natural fibres prior to their use in the initial-RIFT process, as well as the physical properties of the NFRP composite panels after manufacture. The relevant physical properties of the NFRP composite panels made using the initial-RIFT process, together with an assessment of the absorbed water content of the fibres prior to their use in this manufacturing process, are also shown in Table 1.

Several important conclusions may be drawn from these results. Firstly, the water contents of the flax and $\mathrm{CeF}$ are relatively high, being 8.6 and $10.0 \mathrm{wt} \%$, respectively. These values may be compared to the value of $0 \mathrm{wt} \%$ for the equivalent glass fibres. Secondly, during the hightemperature curing of the epoxy matrix, this moisture absorbed by the fibres will be released into the epoxy, as the moisture in the fibres cannot escape from the composite panel during manufacture. Thirdly, this will tend to lead to relatively high void contents, $V_{\mathrm{v}}$, with correspondingly low fibre volume fractions, $V_{\mathrm{f}}$, for the NFRP composite panels manufactured using the initial-RIFT process, as indeed may be seen from Table 1. Fourthly, the moisture diffusing into the epoxy is also likely to (a) decrease the degree of fibre-matrix adhesion and (b) decrease the glass transition temperature, $T_{\mathrm{g}}$, of the epoxy polymeric matrix. The measured values of $T_{\mathrm{g}}$ of the epoxy matrices are given in Table 1, where the measured values for dry, bulk, samples of the epoxy polymers are also shown. The significantly lower values of the $T_{\mathrm{g}}$ for the epoxy polymeric matrices in the NFRP composites produced by the RIFT process compared to those of the dry, bulk, epoxy polymers are clearly evident, with the decrease in the value of the $T_{\mathrm{g}}$ being between 30 and $50{ }^{\circ} \mathrm{C}$. Finally, the effect on the $T_{\mathrm{g}}$ of the water having diffused into the epoxy polymeric matrix may be estimated from the Fox equation [51], assuming that all of the initial moisture in the fibres diffused into the epoxy matrix during the initial-RIFT process. These estimated values for the $T_{\mathrm{g}}$, see Table 1 , indicate that the decreases seen may indeed be readily explained by the moisture in the fibres diffusing into the epoxy matrix during the initial-RIFT manufacturing process.

\section{Optimised-RIFT studies}

The above results clearly indicate the deleterious effect that moisture present in the natural fibres may have upon the properties of the NFRP composites. Hence, in order to remove the moisture, the FF (i.e., in the FF-UD fabric) and the $\mathrm{CeF}$ (i.e., in the $\mathrm{CeF}-\mathrm{PW}$ fabric) were dried in a fan oven at $75{ }^{\circ} \mathrm{C}$ for $12 \mathrm{~h}$ prior to being employed in the RIFT process, as described above. This is termed the optimisedRIFT manufacturing process. 
Table 1 Physical and mechanical properties of the initial-RIFT-manufactured NFRP composites

\begin{tabular}{|c|c|c|c|c|c|c|c|c|c|}
\hline $\begin{array}{l}\text { Fibre type and } \\
\text { architecture }\end{array}$ & $\begin{array}{l}\text { Matrix } \\
\text { formulation }\end{array}$ & $\begin{array}{l}\text { Fibre } \\
\text { volume } \\
\text { fraction } \\
\left(V_{\mathrm{f}}\right)\end{array}$ & $\begin{array}{l}\text { Void } \\
\text { content } \\
\text { fraction } \\
\left(V_{\mathrm{v}}\right)\end{array}$ & $\begin{array}{l}\text { Absorbed } \\
\text { moisture } \\
\text { content of } \\
\text { fibres (wt } \%)\end{array}$ & $\begin{array}{l}\text { Measured } \\
\text { glass } \\
\text { transition } \\
\text { temperature } \\
{\left[T_{\mathrm{g}}\left({ }^{\circ} \mathrm{C}\right)\right]}\end{array}$ & $\begin{array}{l}\text { Bulk ('dry') } \\
\text { glass transition } \\
\text { temperature } \\
{\left[T_{\mathrm{g}}\left({ }^{\circ} \mathrm{C}\right)\right]}\end{array}$ & $\begin{array}{l}\text { Estimated } \\
\text { glass } \\
\text { transition } \\
\text { temperature } \\
{\left[T_{\mathrm{g}}\left({ }^{\circ} \mathrm{C}\right)\right]^{\mathrm{a}}}\end{array}$ & $E_{\text {flex }}(\mathrm{GPa})$ & $G_{\mathrm{c}}\left(\mathrm{J} / \mathrm{m}^{2}\right)$ \\
\hline \multirow{4}{*}{$\begin{array}{l}\text { Unidirectional } \\
\text { flax (FF- } \\
\text { UD) }\end{array}$} & $\mathrm{SiOR} 0$ & 0.31 & 0.15 & 8.6 & 90 & 141 & 79 & $12.5 \pm 1.1$ & $19 \pm 5$ \\
\hline & Si10R0 & 0.23 & 0.13 & 8.6 & 94 & 121 & 66 & $12.9 \pm 0.6$ & $252 \pm 49$ \\
\hline & Si0R9 & 0.38 & 0.17 & 8.6 & 80 & 120 & 65 & $15.1 \pm 0.8$ & $139 \pm 29$ \\
\hline & Si10R9 & 0.33 & 0.16 & 8.6 & 83 & 111 & 59 & $13.2 \pm 0.3$ & $233 \pm 41$ \\
\hline \multirow{4}{*}{$\begin{array}{l}\text { Plain-woven } \\
\text { cellulose } \\
\text { (CeF-PW) }\end{array}$} & SiOR0 & $*$ & 0.14 & 10.0 & 79 & 141 & 71 & $5.7 \pm 0.2$ & $20 \pm 1$ \\
\hline & Si10R0 & $*$ & 0.16 & 10.0 & 80 & 121 & 58 & $6.4 \pm 1.1$ & $23 \pm 2$ \\
\hline & Si0R9 & $*$ & $*$ & 10.0 & $*$ & 120 & $*$ & $*$ & $*$ \\
\hline & Si10R9 & * & * & 10.0 & $*$ & 111 & $*$ & $*$ & $*$ \\
\hline
\end{tabular}

Values shown are the 'mean \pm the standard deviation'

*Values could not be obtained due to the very poor quality of the CeF-PW composites

a The glass transition temperature as estimated using the Fox equation [51]

Table 2 Mechanical properties of the RIFT manufactured GFRP composites

\begin{tabular}{|c|c|c|c|c|c|}
\hline Fibre type and architecture & Matrix formulation & Fibre volume fraction $\left(V_{\mathrm{f}}\right)$ & Void content fraction $\left(V_{\mathrm{v}}\right)$ & $E_{\text {flex }}(\mathrm{GPa})$ & $G_{\mathrm{c}}\left(\mathrm{J} / \mathrm{m}^{2}\right)$ \\
\hline \multirow[t]{4}{*}{ Unidirectional glass (GF-UD) } & Si0R0 & 0.61 & 0.02 & $51.5 \pm 3.4$ & $534 \pm 109$ \\
\hline & Si10R0 & 0.55 & 0.02 & $51.7 \pm 10.6$ & $842 \pm 44$ \\
\hline & Si0R9 & 0.65 & 0.02 & $54.1 \pm 8.7$ & $996 \pm 68$ \\
\hline & Si10R9 & 0.65 & 0.02 & $54.7 \pm 1.9$ & $1257 \pm 56$ \\
\hline \multirow[t]{4}{*}{ Plain-woven glass (GF-PW) } & SiOR0 & 0.41 & 0.02 & $20.0 \pm 1.0$ & $541 \pm 36$ \\
\hline & Si10R0 & 0.38 & 0.02 & $22.6 \pm 4.7$ & $621 \pm 59$ \\
\hline & Si0R9 & 0.42 & 0.02 & $21.9 \pm 0.2$ & $1287 \pm 127$ \\
\hline & Si10R9 & 0.44 & 0.02 & $23.5 \pm 0.6$ & $1372 \pm 73$ \\
\hline
\end{tabular}

Values shown are the 'mean \pm the standard deviation'

The resulting physical properties of the NFRP composites manufactured using the optimised-RIFT process are shown in Table 3. The quality of the composite panels produced appears to be greatly improved: the void content, $V_{\mathrm{v}}$, is now far lower and the fibre volume fraction, $V_{\mathrm{f}}$, is significantly higher. Further, the values of $T_{\mathrm{g}}$ of the epoxy matrices are significantly higher compared to those measured from the composite panels manufactured using the initial-RIFT process, see Tables 1 and 3. Indeed, the average decrease in the measured value of the $T_{\mathrm{g}}$ was only some $20{ }^{\circ} \mathrm{C}$, compared to the $T_{\mathrm{g}}$ of the dry, bulk value for the appropriate epoxy polymer. However, this decrease does suggest that the natural fibres still contained some absorbed moisture, albeit a relatively low concentration. Indeed, the measured $T_{\mathrm{g}}$ values shown in Table 3, compared to the bulk ('dry') values shown in Table 1, indicate that somewhat less than about $2 \mathrm{wt} \%$ of water had been absorbed by the flax and CeF prior to the composite panels being manufactured using the optimised-RIFT process. It is known that the fibres contained $1 \mathrm{wt} \%$ of adsorbed water when taken from the drying oven and it is considered that this small additional amount of water was absorbed by the fibres during the setting-up of the RIFT equipment prior to full resin infusion and subsequent curing. Indeed, the rapid absorption of water by these natural fibres is well established [31].

These significant improvements in the physical properties of the NFRP composites manufactured using the optimised-RIFT process are directly reflected by the major improvements observed in the values of the flexural modulus, $E_{\mathrm{flex}}$, and the interlaminar fracture energy, $G_{\mathrm{c}}$, as may be seen from comparing the results shown in Tables 1 and 3 . The significantly greater values of $E_{\text {flex }}$ for the optimised-RIFT, compared to the initial-RIFT, manufacturing process reflect the higher values of the volume fraction, $V_{\mathrm{f}}$, of fibres produced via employing the former process. However, it is the values of $G_{\mathrm{c}}$ which show truly dramatic improvements by using the optimised-RIFT manufacturing process. For the initial-RIFT studies, the NFRP composites exhibited $G_{\mathrm{c}}$ values ranging from about 20 to $250 \mathrm{~J} / \mathrm{m}^{2}$. 
Table 3 Physical and mechanical properties of the optimised-RIFT manufactured NFRP composites

\begin{tabular}{llllllll}
\hline $\begin{array}{l}\text { Fibre type and } \\
\text { architecture }\end{array}$ & $\begin{array}{l}\text { Matrix } \\
\text { formulation }\end{array}$ & $\begin{array}{l}\text { Fibre volume } \\
\text { fraction }\left(V_{\mathrm{f}}\right)\end{array}$ & $\begin{array}{l}\text { Void content } \\
\text { fraction }\left(V_{\mathrm{v}}\right)\end{array}$ & $\begin{array}{l}\text { Absorbed moisture } \\
\text { content of fibres } \\
(\mathrm{wt} \%)\end{array}$ & $\begin{array}{l}\text { Measured glass } \\
\text { transition temperature } \\
{\left[T_{\mathrm{g}}\left({ }^{\circ} \mathrm{C}\right)\right]}\end{array}$ & $E_{\mathrm{flex}}(\mathrm{GPa})$ & $G_{\mathrm{c}}\left(\mathrm{J} / \mathrm{m}^{2}\right)$ \\
\hline $\begin{array}{c}\text { Unidirectional } \\
\text { flax (FF-UD) }\end{array}$ & Si0R0 & 0.44 & 0.01 & 1 & 126 & $18.7 \pm 0.6$ & $1112 \pm 66$ \\
& Si10R0 & 0.40 & 0.01 & 1 & 119 & $14.2 \pm 0.2$ & $1302 \pm 78$ \\
& Si0R9 & 0.36 & 0.01 & 1 & 107 & $14.1 \pm 0.6$ & $1918 \pm 89$ \\
& Si10R9 & 0.44 & 0.01 & 1 & 110 & $16.1 \pm 0.6$ & $1936 \pm 150$ \\
Plain-woven & Si0R0 & 0.64 & 0.01 & 1 & 99 & $12.1 \pm 0.8$ & $1427 \pm 76$ \\
cellulose (CeF- & Si10R0 & 0.67 & 0.01 & 1 & 98 & $13.0 \pm 1.0$ & $1555 \pm 173$ \\
PW) & Si0R9 & 0.65 & 0.01 & 1 & 94 & $11.4 \pm 1.0$ & $1811 \pm 28$ \\
& Si10R9 & 0.67 & 0.01 & 1 & $12.7 \pm 1.1$ & $1847 \pm 573$ \\
\hline
\end{tabular}

Values shown are the 'mean \pm the standard deviation'

After drying the fibres prior to manufacture, i.e., as in the optimised-RIFT process, the values of $G_{\mathrm{c}}$ now range from about 1110 up to $1900 \mathrm{~J} / \mathrm{m}^{2}$, with some increases being of the order of 70 -fold compared to the values obtained via the initial-RIFT manufacturing process.

\section{Comparison of the mechanical properties of the RIFT-manufactured NFRP (optimised process) and the GFRP composites}

The mechanical properties from the RIFT-processed NFRP (optimised process) and the GFRP composites are compared in Table 4. Further, representative tensile stress versus strain curves are shown in Fig. 3, where it may be seen that these relationships are basically linear in nature. A similar observation was recorded for all the various NFRP and GFRP composite materials that were studied. There are several noteworthy points from these results. Firstly, the values of the flexural modulus, $E_{\mathrm{flex}}$, and uniaxial tensile strength, $\sigma_{\mathrm{t}}$, are clearly significantly greater for the GFRP composites than for the corresponding NFRP composites. This, of course, is to be expected and simply reflects the significantly greater modulus and strength of the glass fibres compared to the flax and cellulose natural fibres. For example, the moduli of the flax, cellulose, and glass fibres are of the order of 60,35 , and $72 \mathrm{GPa}$, respectively, while their tensile strengths are of the order of 700, 675, and $3500 \mathrm{MPa}$, respectively [40]. Secondly, there is no clear trend of the type of epoxy matrix upon the values of the $E_{\mathrm{flex}}$ and $\sigma_{\mathrm{t}}$. This again is as expected, since these mechanical properties are governed by the properties of the fibres, and not the matrix. Thirdly, considering the values of the interlaminar fracture energy, $G_{\mathrm{c}}$, the values for the FF-UD and CeF-PW NFRP composites are typically about $75 \%$ higher than for the corresponding GFRP composites. This reveals the remarkable toughness achieved for the NFRP composites manufactured using the optimised-RIFT process. Finally, for the values of $G_{\mathrm{c}}$, for all the composites studied, there is the general trend of an increased toughness being recorded upon the addition of silica nanoparticles to the epoxy matrix (i.e., the 'Si10R0' matrices), with an even larger increase in the toughness resulting if rubber microparticles are present instead of the $\mathrm{SiO}_{2}$ nanoparticles (i.e., the 'Si0R9' matrices). The hybridtoughened epoxy matrices, which contain both $\mathrm{SiO}_{2}$ nanoparticles and rubber microparticles (i.e., the 'Si10R9' matrices), always possess somewhat the highest values of $G_{\mathrm{c}}$. Thus, the important role that may be played by modifications to the epoxy matrix in order to increase the toughness of the NFRP and the GFRP composites is very clearly demonstrated by the results shown in Table 4.

Finally, Fig. 4 shows the interlaminar fracture energy, $G_{\mathrm{c}}$, plotted against the specific tensile modulus, $E / \rho$, for the NFRP and GFRP composites, as determined from the present study, and for two similar composites employing carbon fibres (CF) $[38,52]$, where $E$ is the tensile modulus and $\rho$ is the density of the composite. The carbon-fibre composites were of a very similar type to the present NFRP and GFRP composites in terms of their fibre architecture and the matrices employed, and they were also manufactured using a resin infusion process. Results are shown in Fig. 4a for the control ('SiOR0') matrix and in Fig. 4b for the hybrid ('Si10R9') matrix. (These two different epoxy matrices were selected for Fig. 4 since they represent, respectively, the lower and upper bounds for the values of $G_{\mathrm{c}}$ that were obtained.) These results clearly show that if a relatively high specific modulus, $E / \rho$, is required, then composites based upon $\mathrm{CF}$ are obviously the materials of choice. However, for applications where the highest values of $E / \rho$ are not an essential requirement, the NFRP composites compete well with the GFRP composites. Considering the toughness, $G_{\mathrm{c}}$, of the various composite materials 
Table 4 Comparison of the mechanical properties of the RIFT-manufactured NFRP (optimised process) and GFRP composites

\begin{tabular}{|c|c|c|c|c|c|}
\hline Fibre type and architecture & Matrix formulation & Fibre volume fraction $\left(V_{\mathrm{f}}\right)$ & $E_{\text {flex }}(\mathrm{GPa})$ & $\sigma_{\mathrm{t}}(\mathrm{MPa})$ & $G_{\mathrm{c}}\left(\mathrm{J} / \mathrm{m}^{2}\right)$ \\
\hline \multirow[t]{4}{*}{ Unidirectional flax (FF-UD) } & SiOR0 & 0.44 & $18.7 \pm 0.6$ & $163 \pm 10$ & $1112 \pm 66$ \\
\hline & Si10R0 & 0.40 & $14.2 \pm 0.2$ & $161 \pm 5$ & $1302 \pm 78$ \\
\hline & Si0R9 & 0.36 & $14.1 \pm 0.6$ & $153 \pm 5$ & $1918 \pm 89$ \\
\hline & Si10R9 & 0.44 & $16.1 \pm 0.6$ & $151 \pm 5$ & $1936 \pm 150$ \\
\hline \multirow[t]{4}{*}{ Plain-woven cellulose (CeF-PW) } & SiOR0 & 0.64 & $12.1 \pm 0.8$ & $122 \pm 1$ & $1427 \pm 76$ \\
\hline & Si10R0 & 0.67 & $13.0 \pm 1.0$ & $130 \pm 3$ & $1555 \pm 173$ \\
\hline & Si0R9 & 0.65 & $11.4 \pm 1.0$ & $142 \pm 2$ & $1811 \pm 28$ \\
\hline & Si10R9 & 0.67 & $12.7 \pm 1.1$ & $147 \pm 2$ & $1847 \pm 573$ \\
\hline \multirow[t]{4}{*}{ Unidirectional glass (GF-UD) } & Si0R0 & 0.61 & $51.5 \pm 8.4$ & $1144 \pm 55$ & $534 \pm 109$ \\
\hline & Si10R0 & 0.55 & $51.7 \pm 10.6$ & $1018 \pm 52$ & $842 \pm 44$ \\
\hline & Si0R9 & 0.65 & $54.1 \pm 8.7$ & $1243 \pm 46$ & $996 \pm 68$ \\
\hline & Si10R9 & 0.65 & $54.7 \pm 1.9$ & $1263 \pm 37$ & $1257 \pm 56$ \\
\hline \multirow[t]{4}{*}{ Plain-woven glass (GF-PW) } & SiOR0 & 0.41 & $20.0 \pm 2.5$ & $442 \pm 12$ & $541 \pm 36$ \\
\hline & Si10R0 & 0.38 & $22.6 \pm 4.7$ & $370 \pm 12$ & $621 \pm 59$ \\
\hline & Si0R9 & 0.42 & $21.9 \pm 0.2$ & $430 \pm 1$ & $1287 \pm 127$ \\
\hline & Si10R9 & 0.44 & $23.5 \pm 0.6$ & $411 \pm 3$ & $1372 \pm 73$ \\
\hline
\end{tabular}

Values shown are the 'mean \pm the standard deviation'
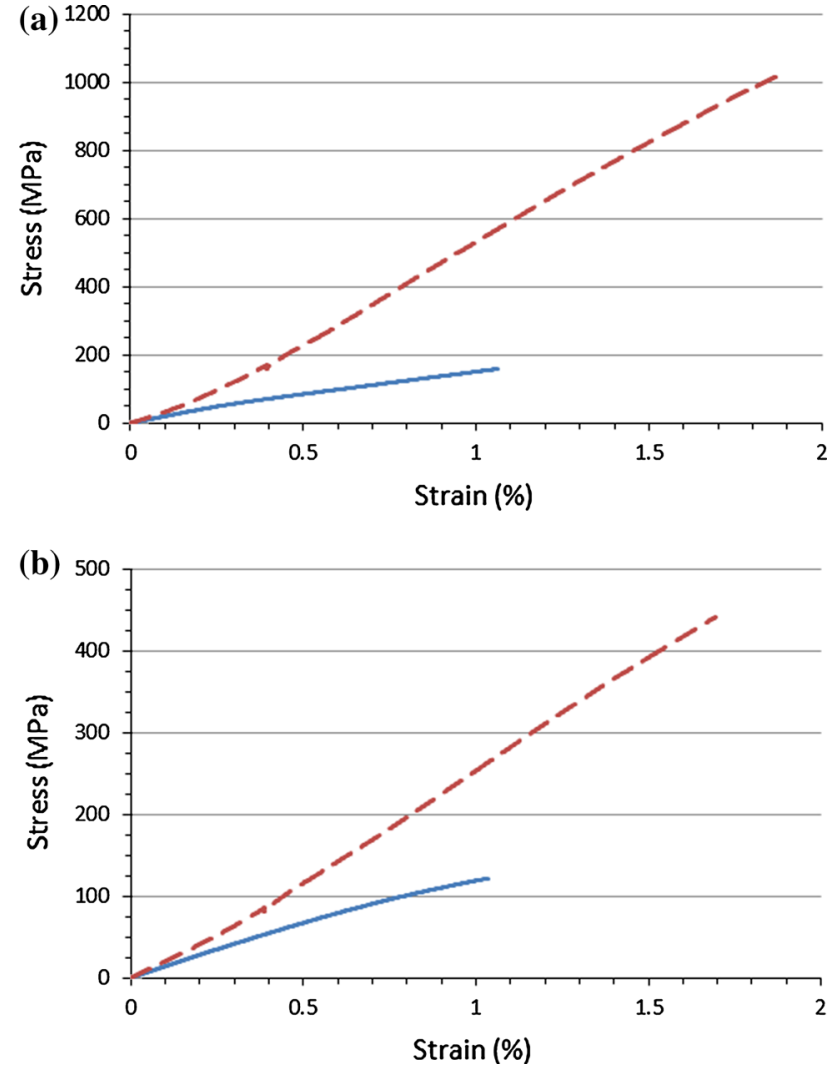

Fig. 3 Tensile stress versus strain curves for the GFRP composites (dashed line) and the NFRP composites (manufactured using the optimised-RIFT process) (solid line) employing the unmodified (i.e., 'Si0R0') epoxy matrix. a For the FF-UD composites. b For the CeFPW composites shown in Fig. 4, the FF-UD and Ce-PW NFRP composites clearly possess the highest values of $G_{\mathrm{c}}$. Further, it is of interest to note that, for all the composites shown in Fig. 4, there is a very positive effect from the presence of the silica nanoparticles and rubber microparticles in the epoxy polymeric matrices, i.e., to give a hybrid-toughened ('Si10R9') epoxy matrix.

\section{Toughening mechanisms}

\section{The RIFT-manufactured NFRP versus the GFRP composites}

Considering firstly the NFRP composites manufactured using the initial-RIFT process (i.e., with no pre-drying of the fibres), SEM images of the fracture surfaces from the DCB tests clearly revealed that many of the fibres had debonded from the epoxy matrix due to relatively poor fibre-matrix adhesion. Since the debonding of the fibres from the matrix has resulted in many clean fibre pull-outs for the FF-UD composite and smooth, unbroken weaves in the CeF-PW composite being observed. This debonding arose from the high moisture contents of up to $10 \mathrm{wt} \%$ present in the natural fibres prior to manufacture. Further, the transformation of this moisture into steam at the high temperatures reached during curing led to relatively high void fraction contents, of up to 0.17 . This was confirmed by the relatively large number of macro-voids seen on the fracture surfaces. As a result of these effects, caused by the 

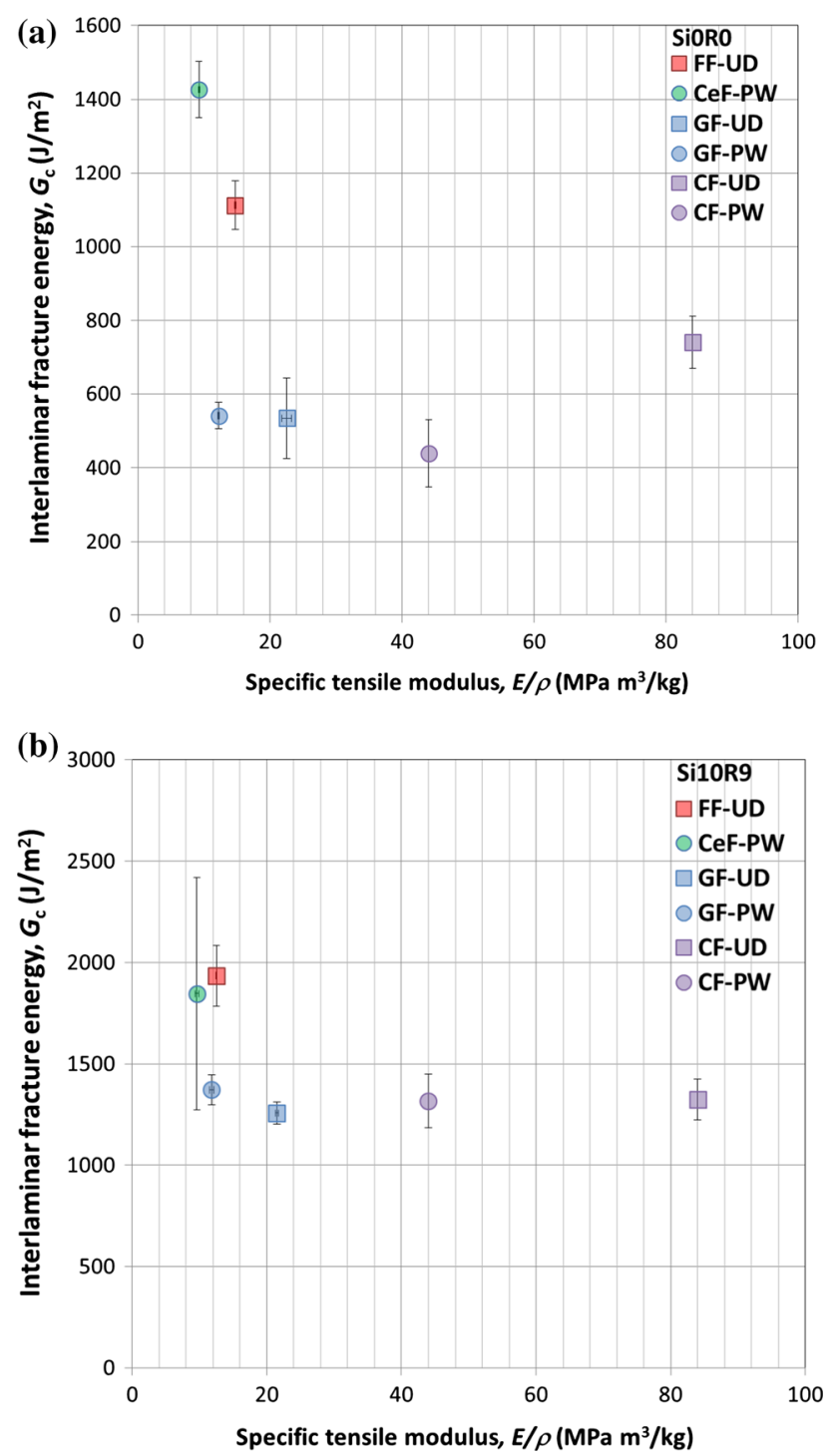

Fig. 4 The interlaminar fracture energy, $G_{\mathrm{c}}$, plotted against the specific tensile modulus, $E / \rho$, for the NFRP composites (manufactured using the optimised-RIFT process) and the GFRP composites, and for two similar composites employing carbon fibres (CF) [37, 52]. a Results for the unmodified ('Si0R0') epoxy matrix, and b for the hybrid-toughened ('Si10R9') epoxy matrix (note the different $y$-axis values)

relatively high moisture content in the natural fibres, very low values of the interlaminar fracture energy, $G_{\mathrm{c}}$, were recorded for the composites produced in the initial-RIFT process, see Table 1 .

Secondly, considering the NFRP composites manufactured using the optimised-RIFT process (i.e., with predrying of the fibres), SEM images of the DCB fracture surfaces are shown in Figs. 5 and 6, for the FF-UD and CeF-PW composites, respectively. The micrographs reveal relatively few clean fibres, indicating that the fibre-matrix adhesion is relatively good. The fracture path of the propagating crack tended to be through the fibres and fibre bundles, and the fracture surfaces were covered with defibrillated and broken fibres and fibre-bundles, as indicated in Figs. $5 b$ and $6 b$. These broken fibres and fibre bundles arose from the extensive fibre and fibre-bundle bridging in the DCB fracture tests, as may be seen in Fig. 7 from the side-view photographs taken during the tests. Thus, the main failure mechanisms are fibre and fibrebundle bridging, which lead to fibre and fibre-bundle breakage and fibre defibrillation. These failure mechanisms will lead to toughening of the composites. Although similar mechanisms were observed for both the FF-UD and the CeF-PW NFRP composites, it was apparent that the extent of fibre defibrillation seen on the fracture surfaces of the FF-UD composites was more extensive than for the CeF$\mathrm{PW}$ composites. This is due to the FF being relatively short and interlocked, with the elementary fibres being bonded together with pectin $[44,53]$. In comparison, the $\mathrm{CeF}$ are relatively more uniform and continuous [44], with fewer intrinsic defects. These factors appeared to make the FFUD composites more susceptible to fibre defibrillation than the CeF-PW composites. On the other hand, it was observed that in the CeF-PW composites, the PW fibre architecture meant that the fibres in the weft and warp directions were mechanically interlocked, see Fig. 6a. Hence, in these composites, it was observed that the fibre and fibre-bundle bridging behind the crack front usually involved a relatively great extent of surface area of delaminated, and bridging, material.

Thirdly, considering the GFRP composites, the fracture surfaces for both the GF-UD and GF-PW composites showed that the degree of fibre-matrix was good, as indeed would be expected. Also, it was observed that fibre bridging and breakage had clearly occurred during the fracture tests for both types of GFRP composite. However, due to the differences in the architectures of the fibre reinforcement, the GF-UD and GF-PW composites exhibited somewhat different fracture mechanisms. The weft and the warp fibres in the PW-based composites were mechanically interlocked, and hence, fibre and fibre-bundle bridging usually involved a relatively greater surface area coverage of delaminated and bridging material. However, the degree of fibre and fibre-bundle bridging was always significantly greater for the NFRP composites compared to the GFRP composites, due to the different microstructures of the natural fibres. This greater extent of the key toughening mechanisms of fibre and fibre-bundle bridging being observed for the NFRP composites is reflected in the higher values of $G_{\mathrm{c}}$ for these materials, as compared to the GFRP composites, as shown in Table 4 and Fig. 4. 

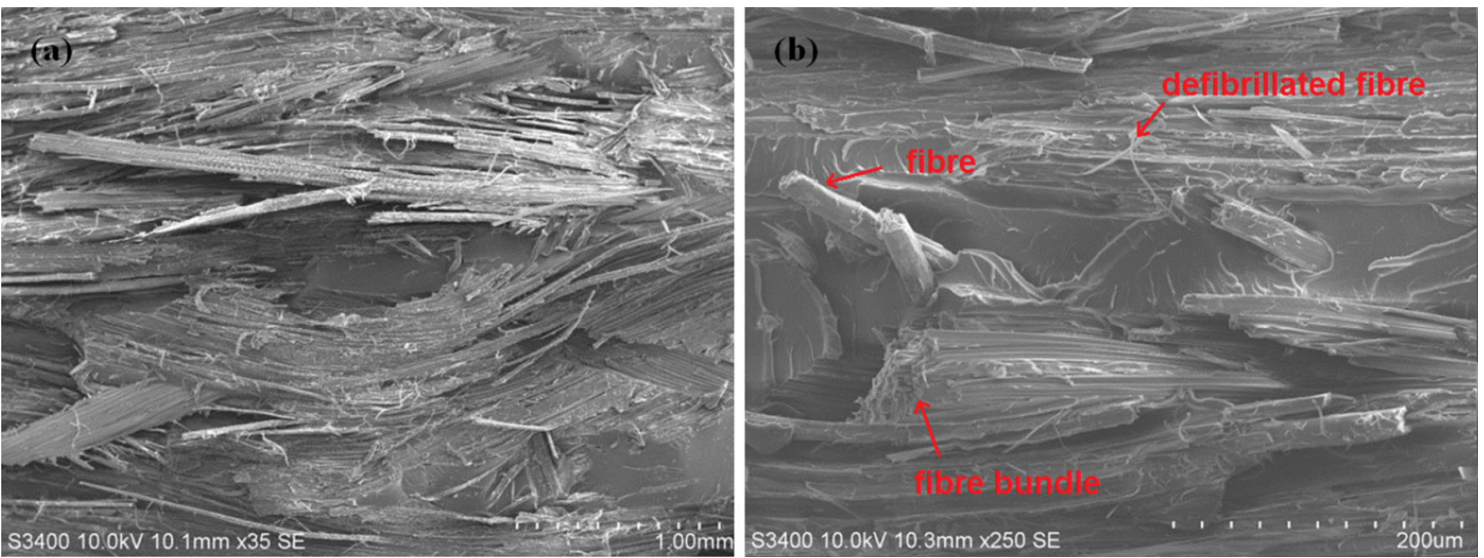

Fig. 5 SEM images of the fracture surfaces of a DCB specimen of the FF-UD composite (employing the 'Si0R0' epoxy matrix) manufactured using the optimised-RIFT process (crack growth from left to right)
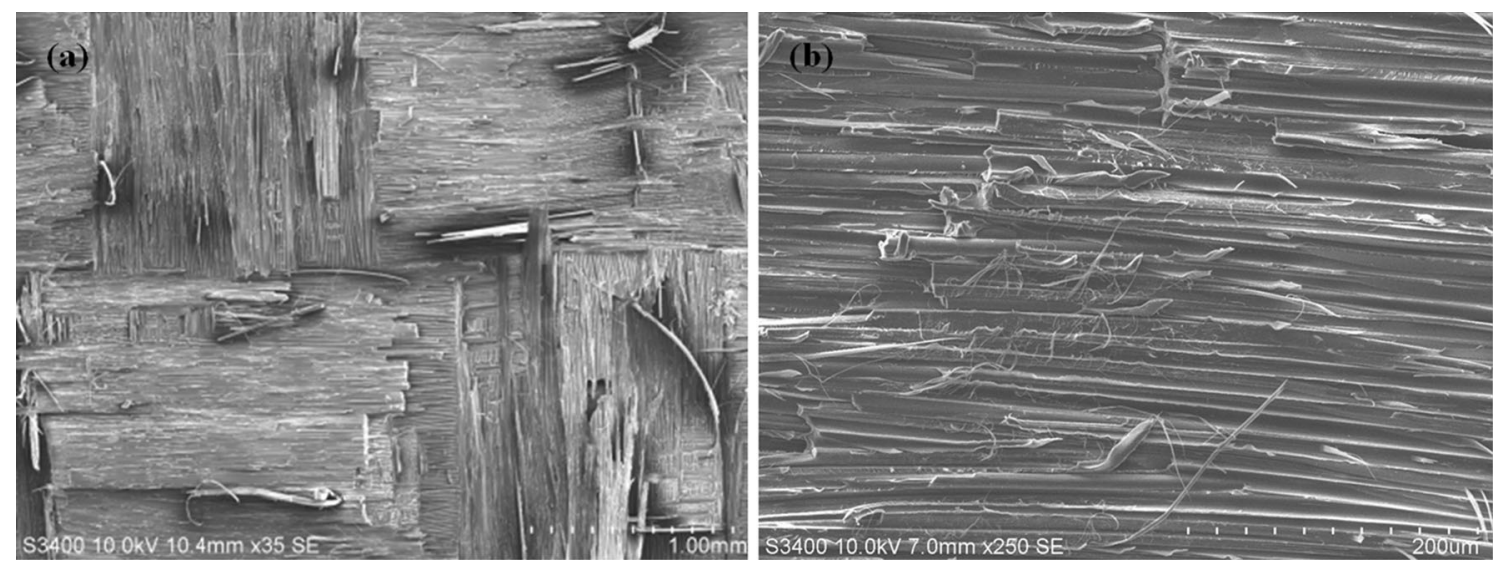

Fig. 6 SEM images of the fracture surfaces of a DCB specimen of the CeF-PW composite (employing the 'Si0R0' epoxy matrix) manufactured using the optimised-RIFT process (crack growth from left to right)
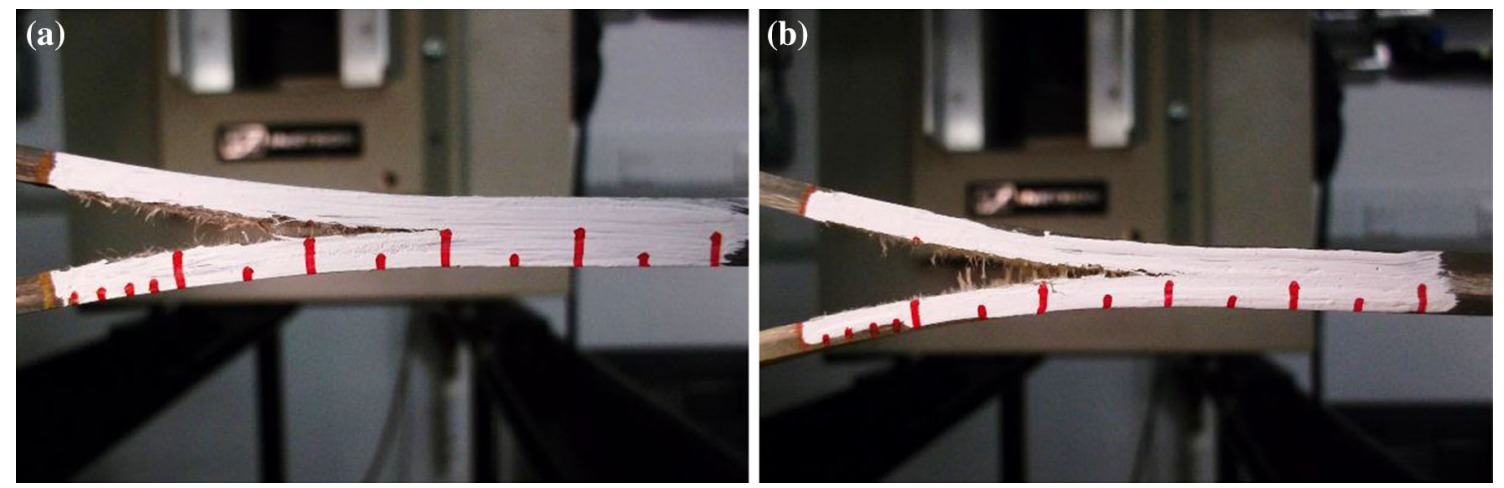

Fig. 7 Side-view photographs of DCB test specimens taken during the interlaminar fracture test, a the optimised-RIFT processed FF-UD composite, and b the optimised-RIFT-processed CeF-PW composite (both composites employed the 'Si0R0' matrix.)

\section{The effect of the type of epoxy matrix employed}

The pre-drying of the natural fibres clearly led to far higher quality of the NFRP composite panels that were manufactured using the optimised-RIFT process, compared to the initial-RIFT process. This led to significantly improved mechanical properties of the NFRP composites manufactured using this former process. Nevertheless, 
from the results shown in Table 4 and Fig. 4, the type of epoxy polymeric matrix employed also plays an important role in increasing the toughness in both the optimised-RIFT NFRP, as well as the GFRP, composites.

The average diameters of the silica nanoparticles and the rubber microparticles when present in the epoxy matrices were $20 \mathrm{~nm}$ and $2.4 \mu \mathrm{m}$, respectively. In the formulations containing only one type of particle, i.e., the 'Si10R0' and 'Si0R9' matrices, the particles were always well dispersed with no signs of particle agglomeration from either the AFM or SEM micrographs. However, for the hybridtoughened matrix, i.e., the 'Si10R9' formulation, there was an indication that the silica nanoparticles had started to aggregate together, but only to a relatively small extent. The toughening mechanisms induced by these types of particles in the epoxy matrix have been well documented $[35,37]$. For example, in the case of the silica nanoparticles, the toughening mechanisms induced by the nanoparticles were identified as (a) localised polymer shear-band yielding around the particles and (b) debonding of the particles followed by polymer void growth of the epoxy polymer. For the rubbery microparticles, the toughening mechanisms are essentially the same, except that the rubber particles are very well bonded to the epoxy matrix and thus they internally cavitate, rather than debond. This internal cavitation enables subsequent polymer void growth of the epoxy polymer. From the studies undertaken on the NFRP and GFRP composites, all the above toughening mechanisms were identified to be operative. Hence, these toughening mechanisms, seen previously in epoxy bulk polymers [38, 54, 55] and epoxy matrix polymers [36, 37], are responsible for the increases seen in the interlaminar fracture energies, $G_{\mathrm{c}}$, as the matrix undergoes modification via the silica nanoparticles and/or the rubber microparticles, as shown in Table 4 and Fig. 4. Finally, it is noteworthy that the hybrid-toughened epoxy matrix always imparts the somewhat highest toughness to the NFRP or GFRP composites.

\section{Conclusions}

Two types of natural fibres were employed in the present work: FF and CeF. The FF was in the form of continuous yarns spun from short, interlocked fibres which were woven into a fabric. The weaving architecture of the flaxfibre fabric was UD. The regenerated $\mathrm{CeF}$ employed was a continuous and non-twisted pure $\mathrm{CeF}$ in a $\mathrm{PW}$ architecture. The NFRP composites employed an anhydride-cured DGEBA epoxy polymer as the matrix. The composites were manufactured employing a RIFT process.

The main aim of the present work was to produce NFRP composites based upon these materials which possess a relatively high value of the interlaminar fracture energy, $G_{\mathrm{c}}$. To achieve this aim, two aspects were studied in detail. Firstly, the effect of absorbed moisture in the fibre on the physical and mechanical properties of the NFRP composites has been investigated. Secondly, in order to increase the toughness of the epoxy polymeric matrix, and possibly the resulting NFRP composite, the matrix was modified with (a) silica nanoparticles, (b) rubber microparticles, and (c) a combination of both of these types of particles to give a hybrid-toughened epoxy matrix. Finally, for comparative purposes, GFRP composites, based upon the same chemical type of epoxy resin matrices and manufactured using the RIFT process, were also studied.

The preliminary studies on the NFRP composites manufactured using the initial-RIFT process clearly showed the deleterious effects that moisture present in the natural fibres may have upon the properties of the NFRP composites, since in the RIFT process, any trapped moisture cannot escape from the composite panel. Thus, it may only diffuse into the epoxy matrix (lowering the glass transition temperature, $T_{\mathrm{g}}$, of the epoxy polymeric matrix and adversely affecting the degree of fibre/matrix adhesion) and be released as steam (creating voids). Hence, an optimised-RIFT-process was developed whereby the FF (i.e., in the FF-UD fabric) and the $\mathrm{CeF}$ (i.e., in the CeF-PW fabric) were dried in a fan oven at $75{ }^{\circ} \mathrm{C}$ for $12 \mathrm{~h}$ prior to being employed in the RIFT process. This reduced the water content of the fibres from around 9 to $10 \mathrm{wt} \%$ to about $1 \mathrm{wt} \%$. Significant improvements in the physical properties of the NFRP composites manufactured using the optimisedRIFT process were recorded and such improvements directly led to major increases being observed in the values of the flexural modulus, $E_{\mathrm{flex}}$, and the interlaminar fracture energy, $G_{\mathrm{c}}$. For example, for the initial-RIFT studies, the NFRP composites exhibited values of $G_{\mathrm{c}}$ ranging from about 20 to $250 \mathrm{~J} / \mathrm{m}^{2}$. After drying the fibres prior to manufacture, i.e., as in the optimised-RIFT process, the values of $G_{\mathrm{c}}$ now ranged from about 1110 up to $1935 \mathrm{~J} / \mathrm{m}^{2}$, with some increases being of the order of 70-fold compared to the values obtained from using the initial-RIFT process. It was also noteworthy that the values of the interlaminar fracture energy, $G_{\mathrm{c}}$, for the NFRP composites were typically about $75 \%$ higher than for the corresponding GFRP composites. This demonstrates the remarkable toughness achieved for the NFRP composites manufactured using the optimised-RIFT process. A study of the toughening mechanisms revealed that, due to the different microstructures of the natural fibres, compared to the glass fibres, the degree of fibre and fibre-bundle bridging was significantly greater for the NFRP composites compared to the GFRP composites, as reflected in the higher values of $G_{\mathrm{c}}$ for the former materials. Finally, for all the composites studied, the values of $G_{\mathrm{c}}$ exhibited a general trend of increased toughness upon the addition of silica nanoparticles to the epoxy matrix (i.e., the 'Si10R0' matrices), with even larger 
increases in the toughness being recorded if rubber microparticles were present instead of the $\mathrm{SiO}_{2}$ nanoparticles (i.e., the 'SiOR9' matrices). The hybrid-toughened epoxy matrices, which contained both $\mathrm{SiO}_{2}$ nanoparticles and rubber microparticles (i.e., the 'Si10R9' matrices), always possessed the highest values of $G_{\mathrm{c}}$. Thus, the important role that may also be played by modifications to the epoxy matrix in order to increase the toughness of the composites was very clearly demonstrated by these results.

Acknowledgement The authors would wish to acknowledge the support of the Singapore Institute of Manufacturing Technology which enabled Mana Techapaitoon to spend one year working in their laboratories.

\section{Compliance with ethical standards}

Conflict of interest The authors declare that they have no conflicts of interest.

Open Access This article is distributed under the terms of the Creative Commons Attribution 4.0 International License (http://crea tivecommons.org/licenses/by/4.0/), which permits unrestricted use, distribution, and reproduction in any medium, provided you give appropriate credit to the original author(s) and the source, provide a link to the Creative Commons license, and indicate if changes were made.

\section{References}

1. Eichhorn SJ, Baillie CA, Zafeiropoulos N, Mwaikambo LY et al (2001) Review: Current international research into cellulosic fibres and composites. J Mater Sci 36:2107-2131. doi:10.1023/A: 1017512029696

2. Eichhorn SJ, Dufresne A, Aranguren M, Marcovich NE et al (2010) Review: Current international research into cellulose nanofibres and nanocomposites. J Mater Sci 45:1-33. doi:10. 1007/s10853-009-3874-0

3. Yan L, Chouw N, Jayaraman K (2014) Flax fibre and its composites-a review. Compos B 56:296-317

4. Dicker MPM, Duckworth PF, Baker AB, Francois G, Hazzard MK, Weaver PM (2014) Green composites: A review of material attributes and complementary applications. Compos A 56: 280-289

5. Goda K, Cao Y (2007) Research and development of fully green composites reinforced with natural fibers. J Solid Mech Mater Eng 1:1073-1084

6. Shah DU (2014) Natural fibre composites: comprehensive Ashbytype materials selection charts. Mater Des 61:21-31

7. Manfredi LB, Rodriguez ES, Wladyka-Przybylak M, Vazquez A (2006) Thermal degradation and fire resistance of unsaturated polyester, modified acrylic resins and their composites with natural fibres. Polym Degrad Stab 91:255-261

8. Liang S, Gning P-B, Guillaumat L (2014) Properties evolution of flax/epoxy composites under fatigue loading. Int J Fatigue 63: $36-45$

9. Gassan J (2002) A study of fibre and interface parameters affecting the fatigue behaviour of natural fibre composites. Compos A 33:369-374

10. Shah DU, Schubel PJ, Clifford MJ, Licence P (2013) Fatigue life evaluation of aligned plant fibre composites through S-N curves and constant-life diagrams. Compos Sci Technol 74:139-149
11. Muralidhar BA (2013) Tensile and compressive behaviour of multilayer flax-rib knitted preform reinforced epoxy composites. Mater Des 49:400-405

12. Duc F, Bourban PE, Plummer CJG, Månson J-AE (2014) Damping of thermoset and thermopolymer flax fibre composites. Compos A 64:115-123

13. Liu Q, Hughes M (2008) The fracture behaviour and toughness of woven flax fibre reinforced epoxy composites. Compos A 39: $1644-1652$

14. Hughes M, Hill CAS, Hague JRB (2002) The fracture toughness of bast fibre reinforced polyester composites-Part I: Evaluation and analysis. J Mater Sci 37:4669-4676. doi:10.1023/A:1020621020862

15. Zhang Y, Li Y, Ma H, Yu T (2013) Tensile and interfacial properties of unidirectional flax/glass fiber reinforced hybrid composites. Compos Sci Technol 88:172-177

16. Liang S, Guillaumat L, Gning P-B (2015) Impact behaviour of flax/epoxy composite plates. Int J Impact Eng 80:56-64

17. Vasconcellos DS, Touchard F, Chocinski-Arnault L (2014) Tension-tension fatigue behaviour of woven hemp fibre reinforced epoxy composite: a multi-instrumented damage analysis. Int J Fatigue 59:159-169

18. Chai MW, Bickerton S, Bhattacharyya D, Das R (2012) Influence of natural fibre reinforcements on the flammability of bio-derived composite materials. Compos B 43:2867-2874

19. Mishra S, Mohanty AK, Drzal LT, Misra M, Parija S, Nayak SK, Tripathy SS (2003) Studies on mechanical performance of biofibre/glass reinforced polyester hybrid composites. Compos Sci Technol 63:1377-1385

20. Vasconcellos DS, Sarasini F, Touchard F, Chocinski-Arnault L, Pucci M, Santulli C, Tirillò J, Iannace S, Sorrentino L (2014) Influence of low velocity impact on fatigue behaviour of woven hemp fibre reinforced epoxy composites. Compos B 66:46-57

21. Yan L, Chouw N (2013) Crashworthiness characteristics of flax fibre reinforced epoxy tubes for energy absorption application. Mater Des 51:629-640

22. Li Y, Chen C, Xu J, Zhang Z, Yuan B, Huang X (2015) Improved mechanical properties of carbon nanotubes-coated flax fiber reinforced composites. J Mater Sci 50:1117-1128. doi:10.1007/ s10853-014-8668-3

23. Kafi AA, Magniez K, Fox BL (2011) Effect of manufacturing process on the flexural, fracture toughness, and thermo-mechanical properties of bio-composites. Compos A 42:993-999

24. Graupner N, Fischer H, Ziegmann G, Müssig J (2014) Improvement and analysis of fibre/matrix adhesion of regenerated cellulose fibre reinforced PP-, MAPP- and PLA-composites by the use of Eucalyptus globulus lignin. Compos B 66:117-125

25. Graupner N, Mussig J (2011) A comparison of the mechanical characteristics of kenaf and lyocell fibre reinforced poly(lactic acid) (PLA) and poly(3-hydroxybutyrate) (PHB) composites. Compos A 42:2010-2019

26. Johnson RK, Zink-Sharp A, Renneckar SH, Glasser WG (2008) Mechanical properties of wetlaid lyocell and hybrid fiber-reinforced composites with polypropylene. Compos A 39:470-477

27. Gindl-Altmutter W, Keckes J, Plackner J, Liebner F, Englund K, Laborie M-P (2012) All-cellulose composites prepared from flax and lyocell fibres compared to epoxy-matrix composites. Compos Sci Technol 72:1304-1309

28. Yan L, Chouw N, Jayaraman K (2015) Effect of UV and water spraying on the mechanical properties of flax fabric reinforced polymer composites used for civil engineering applications. Mater Des 71:17-25

29. Williams C, Summerscales J, Grove S (1996) Resin infusion under flexible tooling (RIFT): a review. Compos A 27:517-524

30. Baley A, Le Duigou A, Bourmaud A, Davies P (2012) Influence of drying on the mechanical behaviour of flax fibres and their unidirectional composites. Compos A 43:1226-1233 
31. Masseteau B, Michaud F, Irle M, Roy A, Alise G (2014) An evaluation of the effects of moisture content on the modulus of elasticity of a unidirectional flax fiber composite. Compos A 60:32-37

32. Van de Weyenberga I, Ivensa J, De Costerb A, Kino B, Baetens E, Verpoest I (2003) Influence of processing and chemical treatment of flax fibres on their composites. Compos Sci Technol 63:1241-1246

33. Lebrun G, Couture A, Laperriere L (2013) Tensile and impregnation behavior of unidirectional hemp/paper/epoxy and flax/paper/epoxy composites. Compos Struct 103:151-160

34. Phillips S, Baets J, Lessard L, Pascal H, Verpoest I (2013) Characterization of flax/epoxy prepregs before and after cure. J Reinf Polym Compos 32:777-785

35. Hsieh TH, Kinloch AJ, Masania K, Taylor AC, Sprenger S (2010) The mechanisms and mechanics of the toughening of epoxy polymers modified with silica nanoparticles. Polymer 51: 6284-6294

36. Manjunatha CM, Sprenger S, Taylor AC, Kinloch AJ (2010) The tensile fatigue behaviour of a glass-fiber reinforced polymer composite using a hybrid-toughened epoxy matrix. J Compos Mater 44:2095-2109

37. Hsieh TH, Kinloch AJ, Masania K, Sohn Lee J, Taylor AC, Sprenger S (2010) The toughness of epoxy polymers and fibre composites modified with rubber microparticles and silica nanoparticles. J Mater Sci 45:1193-1210. doi:10.1007/s10853009-4064-9

38. Manjunatha CM, Taylor AC, Kinloch AJ, Sprenger S (2009) The cyclic-fatigue behaviour of an epoxy polymer modified with micron-rubber and nano-silica particles. J Mater Sci 44:4487-4490. doi:10.1007/s10853-009-3653-y

39. Liu YP, Hu H (2008) X-ray diffraction study of bamboo fibres treated with $\mathrm{NaOH}$. Fibres Polym 9:735-739

40. Techapaitoon M (2015) Tough natural-fibre composites. PhD Thesis, Imperial College London, London

41. Composites_Evolution (2012) Biotex flax unidirectional fabric: Technical Data Sheet. http://www.compositesevolution.com/pro ducts/. Accessed June 2015

42. Porcher_Industries (2012) Porcher Greenlite: Technical Data Sheet. http://www.porcher-ind.com/medias/dossier-presse/pdf/ porcher-dossier-presseEN_3.pdf. Accessed June 2015
43. Masania K (2010) Toughening mechanisms of silica nanoparticle-modified epoxy polymers. $\mathrm{PhD}$ Thesis, Imperial College London, London

44. Cristaldi G, Latteri A, Recca G, Cicala G (2010) Composites based on natural fibre fabrics. In: Dubrovski PD (ed) Woven fabric engineering. Sciyo, Rijeka, Croatia, pp 317-342

45. John MJ, Thomas S (2008) Biofibres and biocomposites. Carbohydr Polym 71:343-364

46. ASTM-D2320 (2012) Standard test method for density (relative density) of solid pitch (pycnometer method). ASTM, West Conshohocken

47. ASTM-E1356 (2014) Standard test method for assignment of the glass transition temperatures by differential scanning calorimetry. ASTM, West Conshohocken

48. ASTM-D790 (2010) Standard test methods for flexural properties of unreinforced and reinforced polymers and electrical insulating materials. ASTM, West Conshohocken

49. ASTM-D3039 (2014) Standard test method for tensile properties of polymer matrix composite materials. ASTM, West Conshohocken

50. BS-ISO-15024 (2001) Fibre-reinforced polymer compositesdetermination of Mode I interlaminar fracture toughness, $G_{\mathrm{IC}}$, for unidirectionally reinforced materials. ISO, Geneva

51. Fox TG (1956) Influence of a diluent and of copolymer composition on the glass temperature of a polymer system. Bull Am Phys Soc Ser II 1:123-123

52. Zhang JN, Deng SQ, Ye L, Zhang Z (2013) Interlaminar facture toughness and fatigue delamination growth of $\mathrm{CF} / \mathrm{EP}$ composites with matrices modified by nano-silica and CTBN rubber. In: 13th International conference on fracture, Beijing, China

53. Charlet K, Baley C, Morvan C, Jernot JP, Gomina M, Bréard J (2007) Characteristics of Hermès flax fibres as a function of their location in the stem and properties of the derived unidirectional composites. Compos A 38:1912-1921

54. Liang YL, Pearson RA (2009) Toughening mechanisms in epoxysilica nanocomposites (ESNs). Polymer 50:4895-4905

55. Bray DJ, Dittanet P, Guild FJ, Kinloch AJ, Masania K, Pearson RA, Taylor AC (2013) The modelling of the toughening of epoxy polymers via silica nanoparticles: the effects of volume fraction and particle size. Polymer 54:7023-7032 